\title{
Effects of Processing on the Properties and Permeability of Pure Gases Through Sol-gel Silica Membranes
}

\author{
B. Topuz, M. Çiftçioğlu and F.Özkan \\ Materials Science and Engineering Graduate Program , İzmir Institute of Technology, \\ URLA, IZMIR,TURKEY
}

Keywords: Sol-gel, silica, membrane, gas permeation, ceramic

\begin{abstract}
N}_{2}, \mathrm{O}_{2}$ and $\mathrm{CO}_{2}$ pure gas permeation through sol-gel derived silica membranes were determined and the effects of processing parameters on the microstructure of the membrane was investigated. Silica sols were prepared in an alcoholic solution by hydrolysis and condensation of TEOS as a function of acid content. The thickness of the silica membranes was determined to be about $2 \mu \mathrm{m}$ and significant infiltration into the support was observed from the SEM pictures. The supported membranes were heat treated in the 50-400 ${ }^{\circ} \mathrm{C}$. The $\mathrm{N}_{2}$ permeabilities of silica membranes varied in the $2.2 * 10^{-10}-2.7 * 10^{-8} \mathrm{~mol} / \mathrm{m}^{2}$.s.Pa range for single layer membranes dipped for $10 \mathrm{~s}$. in the sol. The $\mathrm{CO}_{2}$ permeability of these membranes varied in the $1.2 * 10^{-9}-6.95^{*} 10^{-8}$ $\mathrm{mol} / \mathrm{m}^{2}$.s.Pa range. The sols became viscous and gelled at $50^{\circ} \mathrm{C}$ in 16 hours. The $\mathrm{O}_{2}$ permeability increased with aging time. The optimum dipping time during processing was determined to be 10 seconds. The increase in the acid content of the sols were observed to increase permeabilities of the membranes significantly.
\end{abstract}

\section{Introduction}

The nature of the pore structure is one of the most important factors along with molecular properties and the interaction with the pore walls of gaseous species during their transport through porous membranes. The use of silica polymeric sols can make the design of the pore networks possible for gas separation problems. Highly selective microporous silica membranes with high fluxes could be prepared sol-gel dip coating processes (1). The structure of the thin silica layer mainly depends on the size and the shape of the silicalite polymers and their packing behavior during drying and calcining. Short branched linear polymers are the best making silica microporous membranes with molecular sieving ability (2). Synthesis of silica polymers by the sol-gel process involves the hydrolysation and condensation reactions of starting metal alkoxide (3).

The relative reaction rates of the hydrolysis and condensation reactions depend on the process parameters in the reaction media. Besides the composition of the mixture, the reaction time and temperature are also of great importance (4). The effects of processing parameters like the acid type/amount utilized during sol preparation, sol aging, heat treatment conditions, dipping time on the thin film pore structure and the permeation of pure gases were investigated in this work.

\section{Experimental}

Silica sols were synthesised by acid catalysed hydrolysis and condensation of tetraethyl orthosilicate (TEOS) in ethanol. Predetermined water and acid was added drop-wise to TEOS/ ethanol mixture under constant stirring. During the addition of the acid, water mixture was placed in an ice bath to avoid partial hydrolysis (1). After the addition is complete the stirred reaction mixture was held at $60{ }^{\circ} \mathrm{C}$ for $3 \mathrm{~h}$. The compositions and the codes of the silica sols are given in Table 1. SiD was prepared by co-polymerization of methyltriethoxysilane and TEOS using a two step acid catalyzed process (5). 
Table 1. Synthesis compositions of silica sols.

\begin{tabular}{cclccc}
\hline & TEOS & $\mathrm{HNO}_{3}$ & WATER & EtOH & MTES \\
\hline $\mathrm{SiA}$ & 1 & 0.05 & 6.4 & 3.8 & - \\
$\mathrm{SiB}$ & 1 & 0.085 & 6.4 & 3.8 & - \\
$\mathrm{SiC}$ & 1 & 0.17 & 6.4 & 3.8 & - \\
$\mathrm{SiD}$ & 0.9 & 0.056 & 5.1 & 3.8 & 0.1
\end{tabular}

Silica membranes were prepared by dipping $\mathrm{ZrO}_{2}$ supports into polymeric silica sols. Dipping time was varied from $5 \mathrm{~s}$ to $20 \mathrm{~s}$. Membranes were heat treated from $50{ }^{\circ} \mathrm{C}$ to $400{ }^{\circ} \mathrm{C}$ (heating rate of 3 ${ }^{\circ} \mathrm{C} / \mathrm{min}$ ). Afterwards $\mathrm{SiB}$ sol aged at $50{ }^{\circ} \mathrm{C}$ up to $16 \mathrm{~h}$. was used for investigating the effect of aging and membranes were coded as $\mathrm{SiB}-5, \mathrm{SiB}-10, \mathrm{SiB}-15$ and $\mathrm{SiB}-20$ with respect to the dipping time. The microstructure of the silica membranes deposited on zirconia supports were examined by SEM (Philips XL30S SFEG).

\section{Membrane Test System}

Membrane gas permeance was carried out on a pressure controlled dead-end mode membrane test system as shown in Figure 1. The system consisted of two pressure transducers, teflon membrane module, gas tube $\left(\mathrm{O}_{2}, \mathrm{~N}_{2}\right.$ and $\left.\mathrm{CO}_{2}\right)$ and expansion chamber. The permeate pressure was varied from 2.5 bar to atmospheric pressure. The permeability $\left(\mathrm{mol} \mathrm{m}^{-2} \mathrm{~s}^{-1} \mathrm{~Pa}^{-1}\right)$ of gases through the membrane of effective area, A, $\left(12.5 \mathrm{~cm}^{2}\right)$ into a known permeate reservoir of volume, $\mathrm{V},\left(100 \mathrm{~cm}^{3}\right)$ was calculated according to:

$$
\ln \left(\frac{p_{H}-p_{o}}{p_{H}-p(t)}\right)=\frac{P}{l} \frac{A R T}{V} t
$$

where $\mathrm{p}_{\mathrm{o}}$ is the initial permeate pressure, $l$ is the membrane thickness, $\mathrm{p}_{\mathrm{H}}$ refers to the high or feed pressure while $\mathrm{p}(\mathrm{t})$ is permeate side pressure at time $=\mathrm{t}$. Permeances of gases $(\mathrm{P} / \mathrm{l})$ were determined from the slope of natural logarithm of the pressures versus time.

Pressure Transducer

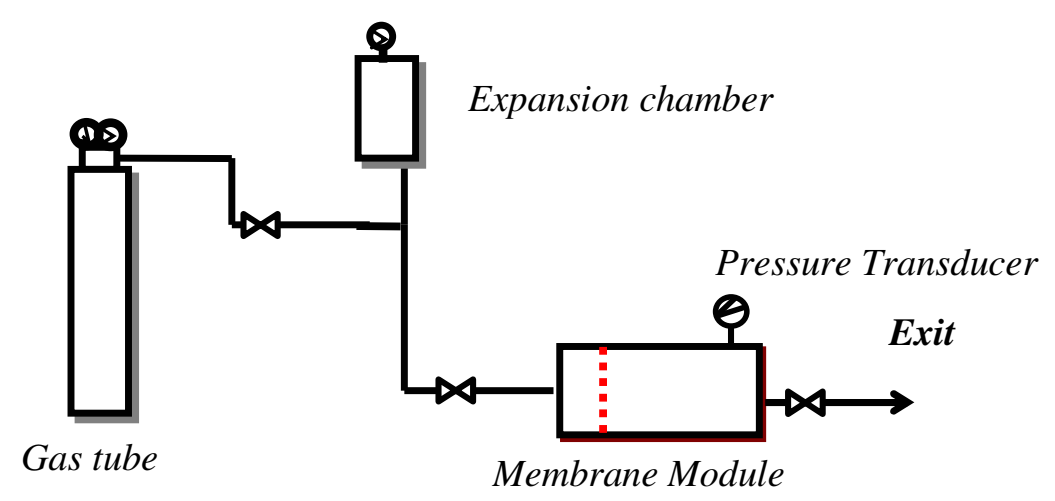

Figure 1. Schematic diagram of the experimental setup for gas permeation.

\section{Results and Discussion}

SEM images of the fracture surfaces shown in Figure 2(a) indicate that discrete silica layers were not formed on the surface of the support. This penetration indicates a good adherence between the top layer and the support. Low permeabilities exhibited by the silica membranes without an intermediate layer was also attributed to the penetration of the sols into the substrate, which increases the effective thickness of the silica layers. Top surface of a silica membrane prepared by dipping twice in a $\mathrm{SiB}$ sol is shown in Figure 3(a). No defects (cracks or pinholes) were observed and the silica layer was formed from very small particles. Figure 3(b) shows the fracture surface of the same membrane and penetration into the support is also clearly visible. 

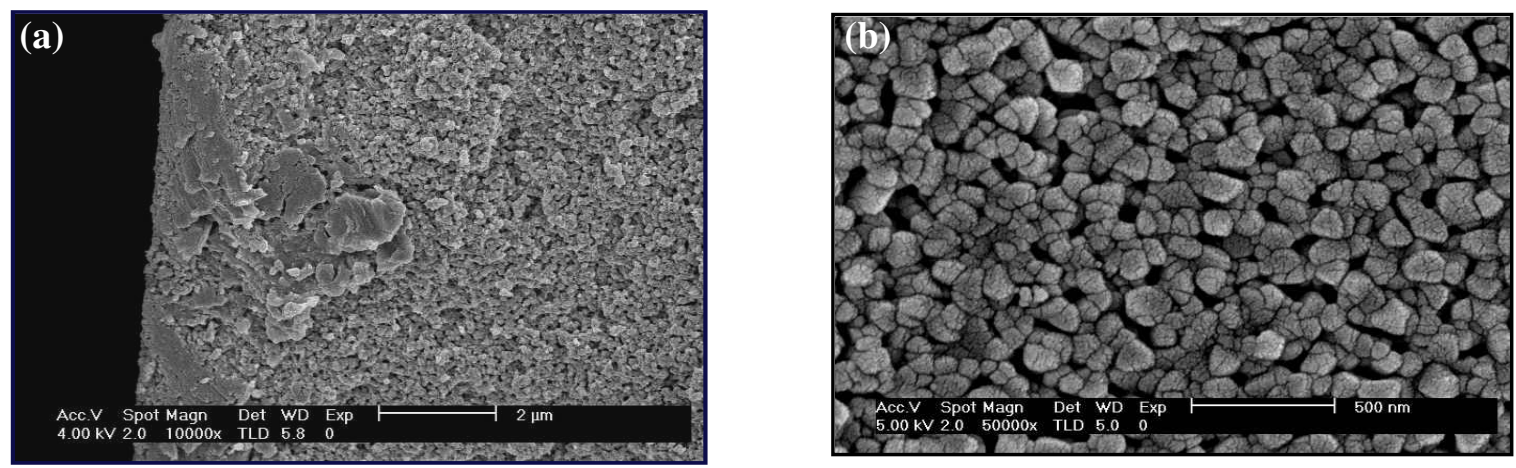

Figure 2.SEM micrograph of $400{ }^{\circ} \mathrm{C}$ treated 1-layer silica membrane: (a) fracture;(b) top surface.
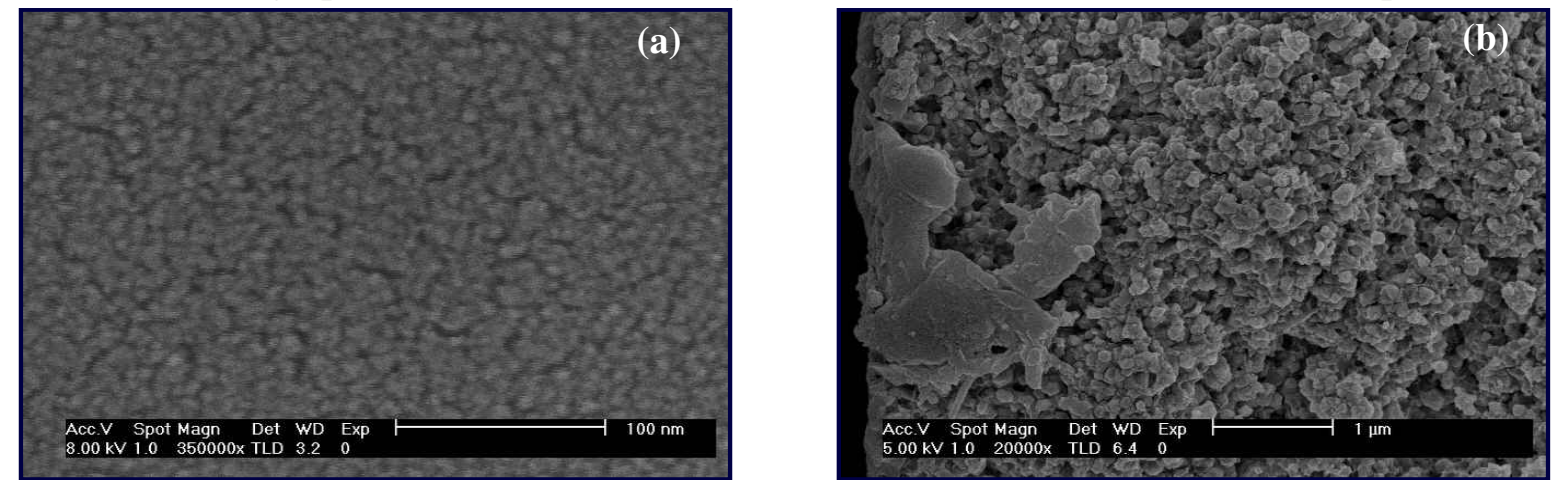

Figure 3.SEM micrograph of $400{ }^{\circ} \mathrm{C}$ treated 2-layer silica membrane:(a) top; (b) fracture surface.

Permeability of $\mathrm{N}_{2}$ was determined from 50 to $400{ }^{\circ} \mathrm{C}$ in order to investigate the thermal stability of silica membranes. $\mathrm{N}_{2}$ Permeability increased with increasing treatment temperature as shown in Figure 4. This is most likely due to partial sintering and microcrack formation during the shrinkage and densification of the membranes. $\mathrm{N}_{2}$ permeability through membranes was lowest value for 10 second dipping and the highest for 20 second dipping for various heat treatment temperatures.

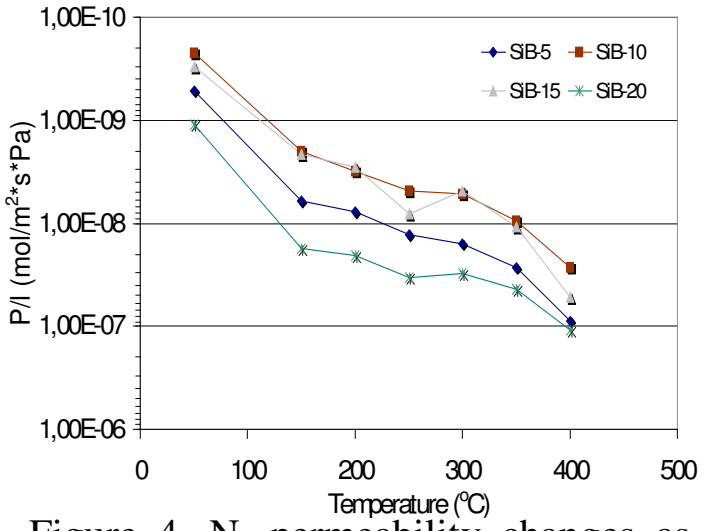

Figure $4 . \mathrm{N}_{2}$ permeability changes as a function of heat treatment $T$.

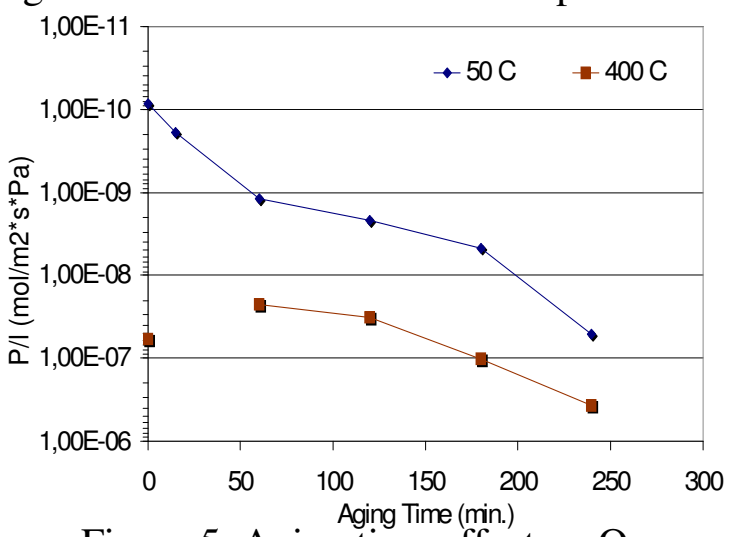

Figure 5. Aging time effect on $\mathrm{O}_{2}$ permeability through SiB-10.

It was also found that application of longer dipping time causes thick gel and resulted in cracking or peeling off the membrane during drying, since the thickness of the membrane is proportional to the square root of the dipping time. On the other hand, a shorter dipping time is not sufficient to form a gel during dipping. Therefore a certain dipping time at certain sol concentration is necessary to obtain a thin membrane layer without defects. The difference in the gas permeation performance might be attributed to this behavior of membranes.

The effect of gel aging time on $\mathrm{O}_{2}$ permeation for the 2-layer 50 and $400{ }^{\circ} \mathrm{C}$ treated silica membranes is given in Figure 5. Permeation rate of $\mathrm{O}_{2}$ through $400{ }^{\circ} \mathrm{C}$ and $50{ }^{\circ} \mathrm{C}$ treated membrane changes significantly with aging time up to 4 hours. Gas permeation performance of the membranes varies significantly due to the changes in the pore structure of the membrane with increasing aging time. 

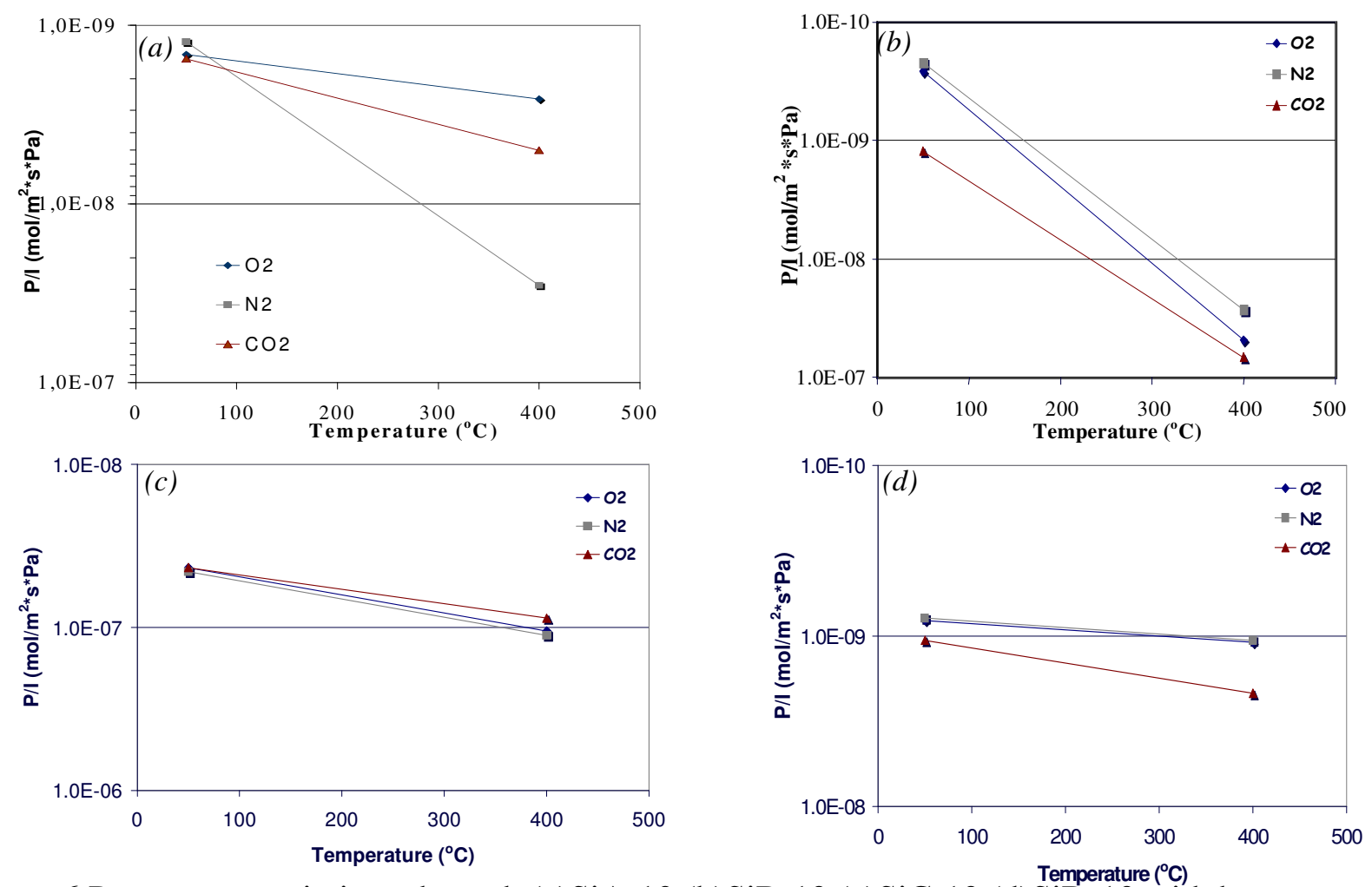

Figure 6.Permeance variations through (a)SiA-10,(b)SiB-10,(c)SiC-10,(d)SiD-10 with heat treatment T.

An increase in the acid content increased the porosity (shown by an increase in gas permeance) which consequently reduced the permselectivity of the gases as shown in Figure 6 which may be due to the faster condensation reaction during sol formation. High permselectivity was obtained for $\mathrm{SiA}$ membranes which had the lowest acid concentration. In contrast to other membranes, permeation of gases through $\mathrm{SiC}$ membrane did not show significant variation in the heat treatment temperature range of $50-400{ }^{\circ} \mathrm{C}$. The permeance results shown in Figure 6(d), seem to be largely independent of heat treatment temperature, though the permeance may be slightly higher at $400{ }^{\circ} \mathrm{C}$ treated membrane while permselectivities nearly remained constant. These results indicate that methyl ligands remained unreacted in the membranes after calcination at $400{ }^{\circ} \mathrm{C}$.

\section{Conclusion}

The results of this work indicate that sol-gel parameters, membrane processing, heat treatment methods and membrane structure may cause significant differences in the permeances of various gases through silica membranes which may make it possible to obtain a specific solution. The crack free 1-layer silica membrane thickness was determined to be about $2 \mu \mathrm{m}$. Permeance of gases through these membranes were independent of the mean pressure across the membranes. The increase in heat treatment temperature increased the permeability of gases. Aging of sols prior to membrane formation caused the increase in permeability of $\mathrm{O}_{2}$ due to change in the pore microstructure of the membranes.

\section{References}

[1]De Vos R. M., Maier W. F., Verweij H., Journal of Membrane Science , 143, pp: 37-51, (1998).

[2]Brinker C.J., Sehgal R., Hietala S.L., Deshpande R., Smith D.M., Loy D. and Ashley C.S., Journal of Membrane Science, 94, pp:85-102, (1994).

[3]Nair, B. N., Elferink J. W., Keizer K., Verweij H., Journal of Sol-gel Science and Technology 8, pp., 471-475 (1997).

[4]Ward D. A., Ko E.I., Ind. Eng. Chem. Res. ,34, pp:421-433 (1995).

[5]Da Costa, J. C. D., Lu G.Q., Zhu H.Y. and Rudolph V., Journal of Porous Materials 6, pp.143151 (1999). 


\section{Euro Ceramics VIII}

10.4028/www.scientific.net/KEM.264-268

Effects of Processing on the Properties and Permeability of Pure Gases through Sol-Gel Silica Membranes

10.4028/www.scientific.net/KEM.264-268.2187

\section{DOI References}

[1] De Vos R. M., Maier W. F., Verweij H., Journal of Membrane Science , 143, pp: 37-51, (1998). 10.1016/S0376-7388(97)00334-7

[2] Brinker C.J., Sehgal R., Hietala S.L., Deshpande R., Smith D.M., Loy D. and Ashley C.S., ournal of Membrane Science, 94, pp:85-102, (1994).

10.1016/0376-7388(93)E0129-8

[3] Nair, B. N., Elferink J. W., Keizer K., Verweij H., Journal of Sol-gel Science and Technology 8, pp., 471475 (1997).

10.1023/A:1018385807541

[5] Da Costa, J. C. D., Lu G.Q., Zhu H.Y. and Rudolph V., Journal of Porous Materials 6, pp.143- 51 (1999). igure 6.Permeance variations through (a)SiA-10,(b)SiB-10,(c)SiC-10,(d)SiD-10 with heat treatment T. b) 10.1023/A:1009635506549 